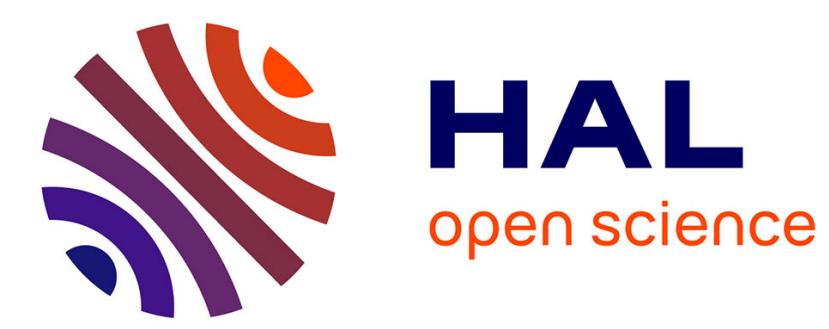

\title{
OXYDATION ET CORROSIONAPPLICATION OF ELLIPSOMETRY TO THE STUDY OF CORROSION PROCESSES
}

J. Kruger

\section{- To cite this version:}

J. Kruger. OXYDATION ET CORROSIONAPPLICATION OF ELLIPSOMETRY TO THE STUDY OF CORROSION PROCESSES. Journal de Physique Colloques, 1977, 38 (C5), pp.C5-129-C5-138. 10.1051/jphyscol:1977516 . jpa-00217164

\section{HAL Id: jpa-00217164 \\ https://hal.science/jpa-00217164}

Submitted on 1 Jan 1977

HAL is a multi-disciplinary open access archive for the deposit and dissemination of scientific research documents, whether they are published or not. The documents may come from teaching and research institutions in France or abroad, or from public or private research centers.
L'archive ouverte pluridisciplinaire HAL, est destinée au dépôt et à la diffusion de documents scientifiques de niveau recherche, publiés ou non, émanant des établissements d'enseignement et de recherche français ou étrangers, des laboratoires publics ou privés. 


\title{
APPLICATION OF ELLIPSOMETRY TO THE STUDY OF CORROSION PROCESSES
}

\author{
J. KRUGER \\ Institute for Materials Research, National Bureau of Standards \\ Washington, D. C. 20234, U. S. A.
}

\begin{abstract}
Résumé. - Les processus de corrosion impliquent des effets locaux dans les couches passives, ces effets conduisent à une augmentation de la rugosité de surface et en conséquence, il est virtuellement impossible de faire de l'ellipsométrie quantitative au niveau actuel tant de l'expérience que de la théorie. Cette communication, en conséquence ne décrit qu'une approche qualitative qui fournit cependant des informations intéressantes sur les processus de corrosion sans détermination exacte des constantes optiques et de l'épaisseur des films. On décrit des mesures de cinétique de repassivation de surfaces nues, des changements dans les films passifs avant sa rupture et des changements dans les crevasses qui conduisent à la corrosion par crevasse.
\end{abstract}

\begin{abstract}
Because corrosion processes involve localized effects in thin passive layers and because these processes lead to surface roughening, it is virtually impossible to do quantitative ellipsometry at todays theoretical and experimental state of the art. This paper, therefore, describes qualitative apparatus that provide valuable insights into corrosion processes without attempting to determine optical constants or exact measures of film thickness. A description is given of measurements of the repassivation kinetics of bare surfaces, changes in the passive film prior to brackdown and changes in a crevices that lead to crevice corrosion.
\end{abstract}

1. Introduction. - Corrosion involves the breakdown of the always present protective film that exists on a metal surface cabable of being used in a given environment. A main issue in studying the mechanism of corrosion processes is how the breakdown of this protective film occurs and the effect of the breakdown process on localized attack. This paper will concentrate on breakdown processes and differs from the usual studies that are directed toward the mechanism of the formation of the protective (passive) film on metals a process considered in many other studies [1-6]. Also, studies concerned with measuring the effects of corrosion after breakdown has been initiated will not be considered here. These have been adequately covered by Hayfield [7-9].

It is difficult to treat breakdown processes using quantitative ellipsometry. For example, a protective film undergoing the breakdown that leads to pitting probably involves such complications as a continually varying refractive index, the possibility of a changing medium, and the formation of other films on top of the original film present at the inception of pitting. Quantitative characterization of the thicknesses and complex refractive indices of all the films involved is questionable under the best of circumstances, but within the current state of the art, it is out of the question for localized corrosion processes. Therefore, this paper will describe certain qualitative uses of ellipsometry that can, however, provide valuable insights into the localized corrosion processes that result from the breakdown of a passive film.
Qualitative ellipsometry implies the use of the ellipsometer in such a way that the optical constants of the film on the surfaces studied are not determined nor is film thickness determined with any accuracy. Instead rough estimates of film thickness are used. Changes in $\Delta$ and $\psi$ can be used in the following ways :

(1) To measure the time during the course of a process when significant changes occur as indicated by abrupt changes in $\Delta$ and $\psi$ and to correlate the $\Delta, \psi$ changes with others, e. g., electrochemical ones.

(2) To observe variations of $\Delta$ and $\psi$ as a function of wavelength under different environmental conditions in order to detect regions of the spectrum where special effects are observed.

(3) To determine what rate laws are operative by measuring variations of thickness (for thin $(<5 \mathrm{~nm}$ ) films, assumed proportional to $\Delta$ ) with time.

This paper will describe applications of some of these qualitative uses of ellipsometry after it first considers some of the special problems associated with the study of corrosion processes.

2. Special problems. - The study of corrosion processes by ellipsometry entails both experimental and theoretical problems which to date have not been solved satisfactorily. The major experimental and theoretical problems encountered in corrosion studies are the following:

2.1 Roughness. - Because corrosion involves both film growth and metal dissolution, many times 
occurring concomitantly, an increasing roughening of the surface being observed is frequently encountered. Recently, Hayfield [8] gave a review of the experimental aspects of roughness as related to corrosion and pointed out that in some instances considerable microroughness did not strongly affect the ellipsometric parameters being measured. In other cases, these effects were observed, but none could be definitely attributed to roughening.

This uncertainty with respect to the effects of roughening or, more precisely, with respect to a quantitative understanding of these effects extends to the theoretical treatment of the optics of roughening. There have been two recent theoretical treatments of roughness. One treatment is a film theory by Fenstermaker and McCrackin [10] where the interfacial roughening was considered to make up a surface film of average optical composition treated by using a Maxwell-Garnet relationship. The other theoretical treatment is that of Ohlidal and Lukes [11] which uses a formulation based on scattering theory. Using controlled surface roughness experiments, Smith [12] found that $\Delta$ and $\psi$ were sensitive to surface roughness with $\psi$ being the parameter more sensitive to roughening for thin films. He found that Ohlidal-Lukes theory was better for bumps, while the FenstermakerMcCrackin theory worked better for pits. In spite of some crude correlations, it is obvious from Smith's findings that neither theory is very satisfactory.

In spite of these problems, it is necessary to point out that crude theoretical approaches to roughness can yield useful qualitative results in corrosion studies. Hayfield has given examples of this [10] and, in more detail, the following example from a study of passive film dissolution [13] accompanied by some metal dissolution in going from passive to active potentials shows how useful information can be obtained. When a passivated iron surface is brought to a potential in the active region, the values of $\Delta$ initially increase with a decrease in film thickness. Figure 1 shows that negative current is measured while this is occurring.

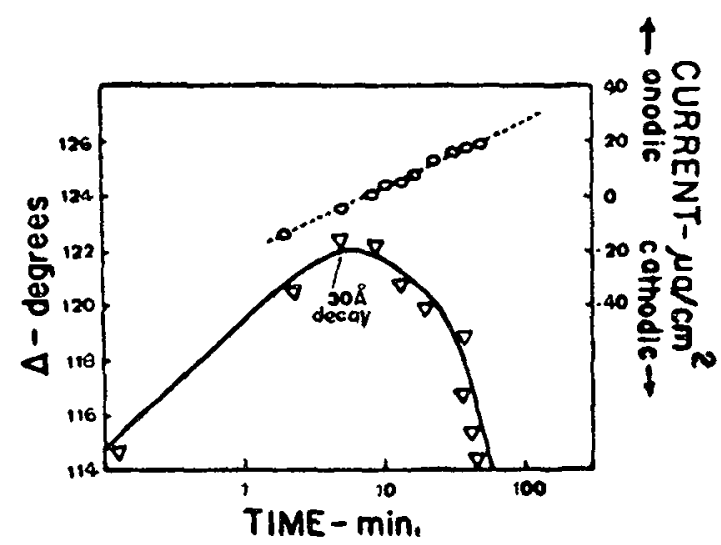

FiG. 1. - The change in the relative phase retardation when a film formed potentiostatically at $+0.8 \mathrm{~V}$ (S. C. E.) in a sodium borate-boric acid solution ( $\mathrm{pH} 8.1$ ) is dissolved by changing the potential to a value where passivity breaks down. (From [13]).
When the current becomes positive, however, $\Delta$ starts to decrease, indicating either film growth or surface roughening. The latter can be detected if subsequent measurements on a cathodically reduced bare surface indicate a change in the substrate optical constants. Usually, the most significant change is that values of $\Delta$ are lower than those measured on a bare surface that has not been held for a significant time at potentials where active dissolution takes place.

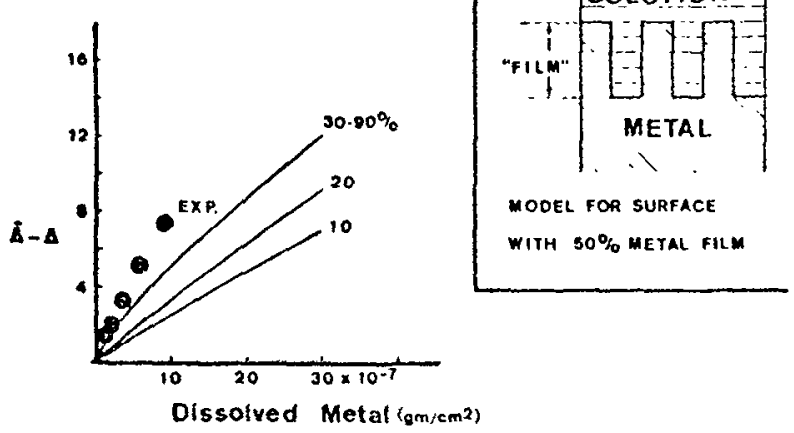

FIG. 2. - A comparison between the experimental effect of roughening by iron dissolution on the departure of $\Delta$ from the smooth film-free value $\bar{\Delta}$ and that calculated using the model shown in the upper right-hand corner. (From [13]).

For illustrative purposes, figure 2 shows why roughening results in a lowering of $\Delta$ and $\psi$ values. Essentially, what this simplified picture assumes is that the roughened but bare surface can be considered as a smooth surface with a film made up of metal islands and solution-filled spaces. The index of refraction of this hypothetical film can be calculated for different degrees of roughening by assuming it to be made up of different percentages of metal and solution, knowing the index of refraction of the metal and the solution. The thickness of the film, is as shown in figure 3,

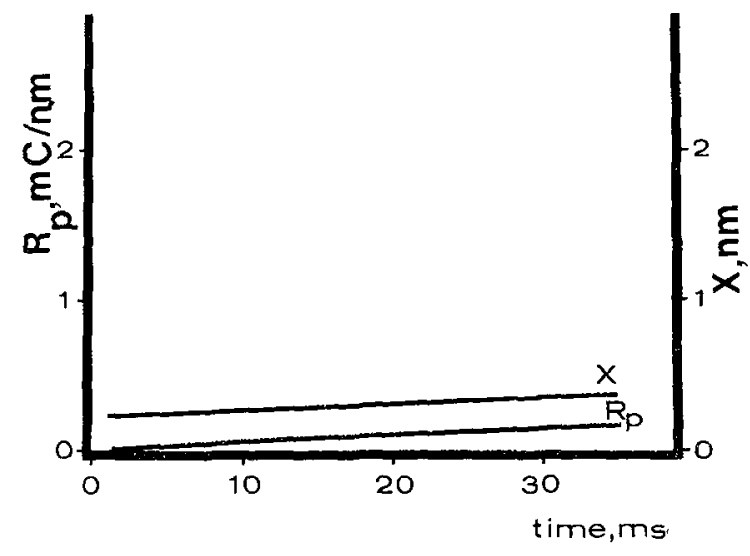

Fig. 3a. - Change in thickness, $x$, and repassivation ratio, $R_{\mathrm{p}}$, after removal of the abrasion wheel of the tribo-ellipsometric apparatus for Ti 8-1-1 in $1 \mathrm{~N} \mathrm{NaNO}_{3}$ at $25^{\circ} \mathrm{C}$. The alloy is at the open-circuit (corrosion) potential - $222 \mathrm{mV}$ (SHE). (From [21]). 


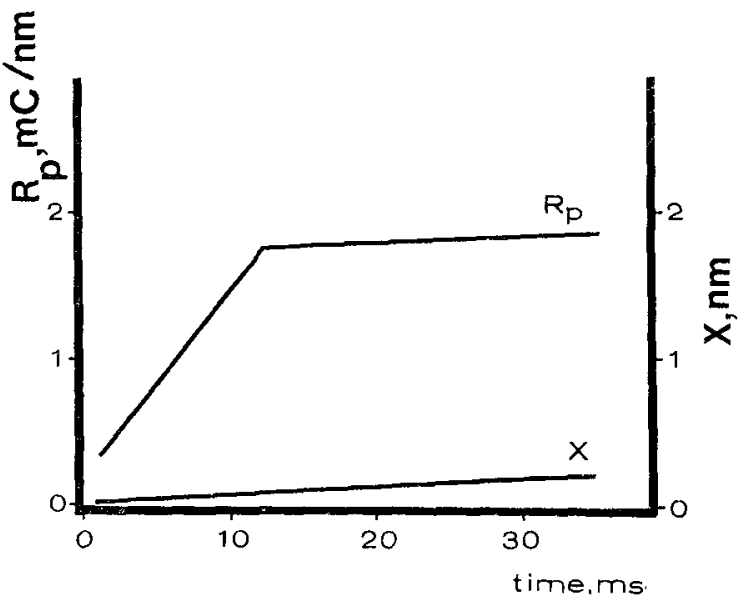

FIG. 3b. - Change in thickness, $x$, and repassivation ratio, $R_{\mathrm{p}}$, after removal of the abrasion wheel of the tribo-ellipsometric apparatus for $\mathrm{Ti} 8-1-1$ in $1 \mathrm{~N} \mathrm{NaCl}$ at $25^{\circ} \mathrm{C}$. The alloy is at the open-circuit (corrosion) potential - $222 \mathrm{mV}$ (SHE). (From [21]).

the height of the metal solution region. This treatment was made more rigorous by Fenstermaker and McCrackin [10] and has also been applied to electrochemical studies by Brusic, Genshaw, and Bockris [14]. They showed that the conclusion of the above simplified picture - that roughening leads to optical effects similar to film growth - is reasonable.

One can use the approach illustrated in figure 2 to learn about other aspects of the corrosion process. For example, it can serve as a starting point to make ellipsometric estimates of the amount of metal going into solution during the roughening of a metal surface by corrosion. As figure 2 shows, if one assumes a film made up of any percentage greater than $30 \%$ metal (the surface is approaching localized roughening with an increase in percentage of metal), the calculated variation of $\bar{\Delta}-\bar{\Delta}$ with amount of metal lost is independent of the percentage of metal making up the hypothetical film. Since the sensitivity of $\bar{\psi}-\psi$ to roughening is much less than $\bar{\Delta}-\Delta$, it is not plotted in figure 2. When the film is made up of less than $30 \%$ metal, the dissolution process is producing less roughening, and the amount of metal going into solution affects $\bar{A}-\Delta$ less sensitively. Here the calculated variation of $\bar{A}-\Delta$ with the amount of metal going into solution does, in contrast to films of $>30 \%$ metal, depend on the amount of metal assumed to be making up the film.

When an estimate of the amount of metal going into solution is made from current measurements and plotted versus $\bar{\Delta}-\Delta$, using the data of figure 10 , it can be seen that the experimental points do not follow the curves derived from the crude model too well. It is, however, closer to the $>30 \%$ metal curve and thus serves to indicate that perhaps the dissolution is localized, possibly at grain boundaries. Using single crystals where the grain boundaries were eliminated showed that the assumption had merit because $\Delta$ did not change direction as in figure 1 but leveled off at a constant value. Thus this simplistic approach to roughening yielded the important information that breakdown of passivity first occurs at grain boundaries.

2.2 FILM INHOMOGENEITY. - Because corrosion involves reactions between complex metal surfaces (usually alloy surfaces) and complex environments, the films produced are non-uniform both with regard to thickness and composition. Hayfield [10] has considered the variation of thickness involving, besides simple thickness variations, isolated mounds or patches of corrosion products as well as a roughness problem. It can be so considered but differs from the roughness just discussed where only a roughening of the metal substrate is considered. This problem of corrosion product film roughness introduces another degree of complexity because not only the metal's refractive index but also the refractive index of the film determines the $\Delta$ and $\psi$ measured. The usual approach has been to use Winterbottom's [1] suggestion of considering the thickness as the average amount of corrosion product in the film as being equivalent to that of a uniform film of the thickness obtained from the calculations based on a uniform film. Hayfield [10] has given a number of examples where useful corrosion information has been obtained using essentially this approach. In many cases, the same approach is used with regard to refractive index, i. e., settling for an average value assuming a compositionally homogeneous film.

For thicker films, it may not be necessary to assume complete compositional homogeneity. Green, Mengelberg, and Yolken [15] studying the tarnishing of brass in ammoniacal solutions were able to detect in thick films (>1000 $\AA$ ) transitions in film compositions from non-absorbing to absorbing films and to determine at what point in the growth process this transition occurred.

Additional theoretical and experimental problems arise at the other extreme - very thin (partial monolayer) films. Here the theoretical problems are the most formidable. Experimentally, it has been estimated that \pm 0.02 of a monolayer can be detected [16] Theoretically, the basic problem in the ellipsometry of partial monolayers is to develop realistic two-dimensional substitutes for the three-dimensional quantities, index of refraction, and film thickness, and, once having chosen these, to relate them in a meaningful way to the $\Delta$ and $\psi$ obtained ellipsometrically. Attempts have been made by a few workers [17-19]. However, all of these hitherto attempted treatments described assume atomically flat surfaces. As crystal models and the results of LEED studies show, there exists on perfect single crystal surfaces an inherent roughness with hill and valleys of one- or two-atom dimensions. When one is talking about partial monolayer coverage, the interpenetration of the adsorbed molecules with these surface variations must be taken into consideration. 
It is obvious that from a theoretical standpoint, the ellipsometry of partial monolayers, (e. g., adsorbed corrosion inhibitors) is still in an elementary stage.

3. Breakdown. - As pointed out earlier, breakdown of passivity leading to forms of localized corrosion such as stress corrosion, pitting or crevice corrosion is not very amenable to studies using quantitative ellipsometry seeking characterization of film optical constants and precise measurement of film thickness. This is so because of the localized nature of the attack, the production of patches of corrosion products of varying compositions and the problems of roughening. Nevertheless, by using qualitative ellipsometry, Ambrose and Kruger [20,21] have shown that changes in $\Delta$ and $\psi$ can be used in a fruitful way to do the following : 1) compare the rate of repassivation of a bare surface for a given metal in different environments ; 2) measure the time during the course of a process when significant changes occur as indicated by abrupt changes in $\Delta$ and $\psi$ and to correlate the $\Delta$, $\psi$ changes with others, e. g., electrochemical ones; 3) observe variations of $\Delta$ and $\psi$ as a function of wavelength under different environmental conditions in order to detect regions of the spectrum where special effects are observed ; 4) determine what rate laws are operative by measuring variations of thickness (for thin $(<5 \mathrm{~nm}$ ) films, assumed proportional to $\Delta$ ) with time.

A description of the application of some of these qualitative uses of ellipsometry to the study of (a) repassivation kinetics as applied to stress corrosion, (b) the initiation of pitting, and (c) the initiation of crevice corrosion follows.

3.1 RePASSIVATION KINETICS. - Ellipsometry seeks to measure in this application the rate at which a protective film grows on a surface once the previous film is removed. This process is of great importance to stress corrosion cracking (SCC) where films are ruptured when a metal is stressed; the rate at which the surface is repassivated determines the length of time the unprotected metal can be attacked by an environment. To measure this repassivation process, Ambrose and Kruger [22] developed a technique called triboellipsometry. Their technique uses a small abrasive polishing to remove the protective film on a metal surface while it is immersed in an aqueous solution. This abrasion step leaves the metal surface in a cold worked state, but, since the tip of a growing stress corrosion crack is continually undergoing plastic strain, the growth rate of a film on the abraded surface is probably closer to that which occurs at the crack tip than the rate for a strain free surface. The polishing wheel is then quickly withdrawn, and ellipsometric and electrochemical current transients are recorded on an oscilloscope. The current is a measure of both the film growth and the metal dissolution that occur during repassivation. The ellipsometer measures mainly film regrowth.
While there are other electrochemical techniques [23, 24] for measuring repassivation kinetics by using current decay measurements, the triboellipsometric technique allows one to determine how much of the current is involved in film repair and how much is involved in metal dissolution. It cannot do this quantitatively because it is difficult to measure the amount of bare surface produced by abrasion so that the current density is difficult to determine. Moreover, exact measurements of film thickness by ellipsometry on the abraded surface are difficult. (One can, however, measure changes in $\Delta$ and $\psi$ and relate these changes to thickness changes that are reasonable estimates even when the optical constants of the film are not well known [25]). To overcome the difficulties of inexact current density and film thickness measurements, a parameter has been defined $[20,21]$ that allows one to compare the repassivation behaviors of a given metal in different environments and thus use it as a diagnostic tool for estimating which environment would have the greater likelihood to promote stress corrosion. This parameter $R_{\mathrm{p}}$, the repassivation ratio, uses the experimentally measured variables of total current, $i_{\mathrm{r}}$, and film thickness, $x$, in the form of a ratio, designated $R_{\mathrm{p}}$, and is given by

$$
R_{\mathrm{p}}=\frac{\int_{0}^{t} i_{\mathrm{T}} \mathrm{d} t}{x} .
$$

Since

$$
\int_{0}^{t} i_{\mathrm{T}} \mathrm{d} t=Q_{\mathrm{T}} \quad \text { and } \quad x=\frac{10^{4} M_{\mathrm{f}}}{z_{\mathrm{f}} F_{\rho \mathrm{f}} A} Q_{x},
$$

then

$$
R_{\mathrm{p}}=\frac{Q_{\mathrm{T}}}{k Q_{x}}
$$

where

$$
k=\frac{10^{4} M_{\mathrm{f}}}{z_{\mathrm{f}} F_{\rho \mathrm{f}} A} .
$$

If we assume that $Q_{\mathrm{T}}=Q_{x}+Q_{\mathrm{d}}$, then

$$
R_{\mathrm{p}}=\frac{Q_{x}+Q_{\mathrm{d}}}{k Q_{x}}=\frac{1}{k}\left[1+\frac{Q_{\mathrm{d}}}{Q_{x}}\right]
$$

where $Q_{\mathrm{d}}=$ charge consumed by metal dissolution, and $\frac{\mathrm{d} Q_{\mathrm{d}}}{\mathrm{d} t}=i_{\mathrm{d}}$ is the current consumed by metal dissolution $\left({ }^{1}\right)$.

$R_{\mathrm{p}}$ is defined above using the experimentally measured total current rather than current density because

(1) The quantities used in equations (1) to (7) are as follows : $i_{\mathrm{T}}$, total current consumed during repassivation; $t$, elapsed time ; $x$, film thickness ; $Q_{\mathrm{T}}$, total charge consumed in repassivation ; $M_{\mathrm{f}}$, molecular weight of film; $Z_{\mathrm{f}}$, valence of metal ion in film ; $F$, Faraday constant ; $\rho_{\mathrm{f}}$, density of film ; $A$, area of bare metal produced ; $Q_{x}$, charge consumed in film formation;

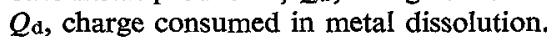


an estimation of the area available for the repassivation reaction is difficult. However, it is sometimes useful to express $R_{\mathrm{p}}$ as a dimensionless variable, designated $R_{p}^{*}$ and equal to

$$
\frac{Q_{t}}{Q_{x}}=1+\frac{Q_{\mathrm{d}}}{Q_{x}}
$$

since results would be independent of the particular experimental procedures and apparatus employed. Although $R_{\mathrm{p}}$ and $R_{\mathrm{p}}^{*}$ differ in magnitude only by the constant, $k, R_{\mathrm{p}}$ values are determined directly from experimental measurements; therefore, interpretation of experiments are usually based on $R_{\mathrm{p}}$ values. $R_{\mathrm{p}}$ is a cumulative index of the extent of corrosion attack. Its time derivative is also useful as an indicator of any abrupt variation which might occur during the repassivation process, for example, completion of monolayer coverage. Differentiating $R_{\mathrm{p}}$ with respect to time gives

$$
\begin{aligned}
\frac{\mathrm{d} R_{\mathrm{p}}}{\mathrm{d} t} & =\frac{1}{k}\left[\frac{Q_{x} \frac{\mathrm{d} Q_{\mathrm{d}}}{\mathrm{d} t}-Q_{\mathrm{d}} \frac{\mathrm{d} Q_{x}}{\mathrm{~d} t}}{Q_{x^{2}}}\right] \\
& =\frac{1}{k}\left[\frac{Q_{x} i_{\mathrm{d}}-Q_{\mathrm{d}} i_{x}}{Q_{x^{2}}}\right] \\
& =\frac{1}{k}\left[\frac{i_{\mathrm{d}}}{Q_{x}}\right]-\frac{1}{k}\left[\frac{Q_{\mathrm{d}} i_{x}}{Q_{x^{2}}}\right] .
\end{aligned}
$$

In this derivation, the cathodic current, $i_{\mathrm{c}}$, has been neglected. This is resonable because it is generally quite low except in acid solutions, hence negligible compared to $i_{\mathrm{a}}$, the anodic current, when the anodic overvoltage is high.

The values of $R_{\mathrm{p}}$ and $\mathrm{d} R_{\mathrm{p}} / \mathrm{d} t$ can be used to distinguish between metal dissolution and film repair, and thus to provide parameters for predicting stress corrosion cracking susceptibility. Consider the following conditions corresponding to processes occurring within a stress corrosion crack: (A) $i_{\mathbf{d}} \gg i_{x}$ and $\mathrm{d} R_{\mathrm{p}} / \mathrm{d} t>0\left(i_{\mathrm{d}}\right.$ and $i_{x}$ are the currents associated with metal dissolution and film growth respectively); this would correspond to the case where general corrosion without any repassivation was occuring. (B) $i_{x} \gg i_{\mathrm{d}}$ and $\frac{\mathrm{d} R_{\mathrm{p}}}{\mathrm{d} t} \simeq \frac{1}{k} \frac{Q_{\mathrm{d}} i_{x}}{Q_{x^{2}}}$ (from eq. (7)); this corresponds to virtually instant repassivation with no metal dissolution and little susceptibility to SCC. (C) $i_{x} \simeq i_{\mathrm{c}}$ and $\mathrm{d} R_{\mathrm{p}} / \mathrm{d} t \simeq 0$. (D) $\mathrm{d} x / \mathrm{d} t>0$ (at large values of $t$ ); here the film formed is not protective but is similar in characteristics to (A) because general corrosion or pitting results. (E) $\mathrm{d} x / \mathrm{d} t \simeq 0$ (at large values of $t$ ). These situations would be those most consistent with the initiation and propagation of stress corrosion cracks attributable to a metal dissolution mechanism that is dependent upon the rate of repassivation. Thus, a relatively large value of $R_{\mathrm{p}}$, with small values of $\mathrm{d} R_{\mathrm{p}} / \mathrm{d} t$ and $\mathrm{d} x / \mathrm{d} t$, indicates that metal dissolution accompanies film regrowth. Repas- sivation eventually occurs, thus protecting the walls of the advancing crack and restrincting propagation of the crack to the area directly at its tip.

Figures $3 a$ and $b$ show experimental results obtained on a titantum alloy exposed to environments in which the alloy is both susceptible and nonsusceptible to SCC. $R_{\mathrm{p}}$ for the susceptible environment $\left(\mathrm{NaNO}_{3}\right)$ is $0.3 \mathrm{~m} \mathrm{coul} / \mathrm{nm}$ at the time of monolayer formation and is $2.0 \mathrm{~m} \mathrm{coul} / \mathrm{nm}$ in the susceptible environment $(\mathrm{NaCl})$.

3.2 EXAMINE THE OPTICAL AND ELECTROCHEMICAL CHANGES THAT LEAD to PITTING. - For studies of pitting, the ellipsometer is more applicable to an investigation of the processes leading to film breakdown and pitting than it is for studying the progress of pitting. Once a film has broken down and pitting is actively taking place, the formation of corrosion products obscures the pitting process and one is simply looking at film formation. Thus the ellipsometer is best employed in studying prepitting rather than pitting.

The process of pit initiation involves a change in the protective ability of a passive film on a metal surface at discrete sites so that extensive metal dissolution occurs. Such a description does not assume any of the many proposed mechanisms for pit initiation [26] at these sites. Once metal dissolution begins, the initiation process is over, and the pit propagation stage is underway with its usually accompanying deposition of non-protective corrosion products on top of the growing pit. Ellipsometry is especially applicable to the initiation stage where subtle changes in the protective film can be observed upon introduction of the damaging species (usually chloride ions) that cause film breakdown. During pit propagation, the usually accompanying surface roughening and corrosion product deposition make the application of ellipsometry more difficult.

Three ways in which pit initiation can be studied by ellipsometry will be described: (a) induction time measurements, (b) film property changes during the induction period, and (c) potential effects on breakdown. All of these studies, used to illustrate the application of qualitative ellipsometry to pitting, are concerned with the pitting of passivated iron surfaces by chloride ions.

a) Induction time measurements. - More complete experimental details on these measurements are given in a paper by Ambrose and Kruger [27]. The experimental procedure involved potentiostatically polarizing pure iron surfaces in sodium borate-boric acid solutions at potentials that promoted the formation of a passive film. When the thickness of the passive film was no longer changing for all practical purposes, measured amounts of solutions of chloride ions were added to the solution already in the experimental cell. The onset of pitting was then observed both by ellipsometric and current density measurements. Figure 4 


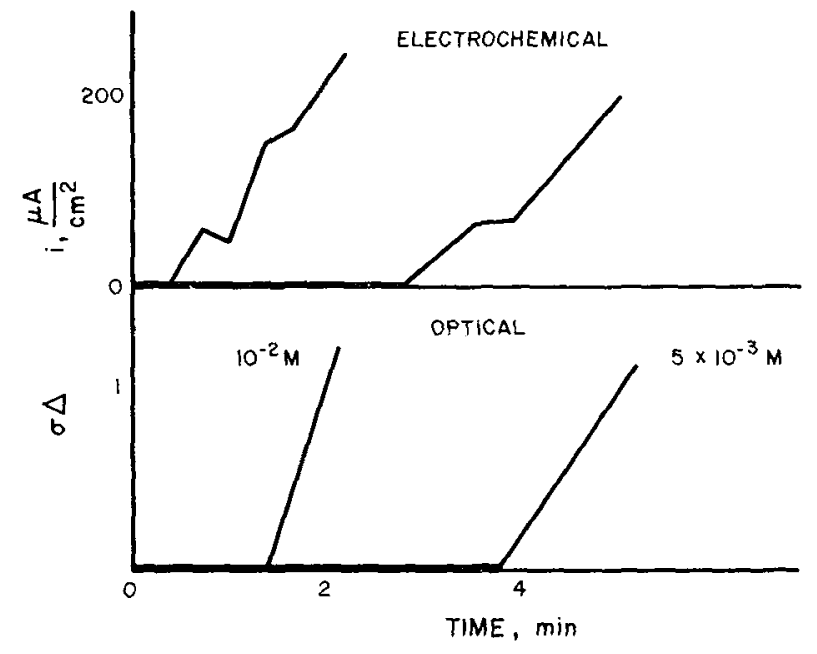

FIG. 4. - The effect of chloride ion concentration on breakdown after introduction of chloride into a boric acid-sodium tetraborate buffer solution ( $\mathrm{pH}=8.4$ ) films were grown for 100 minutes. The breakdown was observed by simultaneously following changes in phase retardation $(\delta \Delta)$ and current, potential being held constant at +1.04 V SHE. (From [27]).

shows the effect of chloride ion concentration on induction time, defined as the time required before pitting is initiated by passive film breakdown at discrete sites. The initiation of pitting is signalled both optically and electrochemically but at two different times, $t_{1}$ and $t_{2}$. The first indication of breakdown at $t_{1}$ is signalled by an increase in current which corresponds to a rapid increase in the rate of metal dissolution. The second indication at $t_{2}$ involves a rapid change in $\Delta$ (a decrease) and probably corresponds to the formation of a corrosion product film at the breakdown site. This is suggested by the fact that if sufficient time is allowed, one can observe the deposited corrosion products visually without the aid of the ellipsometer. The electrochemically measured induction time $t_{1}$ is dependent on a number of factors such as concentration (see fig. 4), temperature of initial passive film formation, time allowed for passive film growth prior to $\mathrm{Cl}^{-}$introduction and others, but $t_{2}-t_{1}$ was found to be approximately constant (around $1 \mathrm{~min}$ ). It indicates that such deposition is not coincidental with breakdown.

All of these ellipsometric studies of induction times were carried out at one wavelength, $546.1 \mathrm{~nm}$. They provided the following data that are useful in developing an understanding of the localized corrosion processes of pitting:

(a) No detectible optical changes due to thinning or refractive index variations (when using $\lambda=546.1 \mathrm{~nm}$ ) occur in the passive film prior to the initiation of pitting.

(b) Corrosion product deposition is not simultaneous with pit initiation but requires its own induction period of around $1 \mathrm{~min}$.

The implications of these useful results revealed by qualitative ellipsometry on the mechanism of pitting are given elsewhere [26].

b) Film property changes during the induction period. - Extending the induction period studies, McBee and Kruger [28] sought to determine whether optical changes could be detected during the time before breakdown (the induction time) if ellipsometric measurements were made using a light source that permitted measurements at a number of wavelengths in the visible region of the spectrum. They found for the same system as that of Ambrose and Kruger that for a few wavelengths, changes in $\Delta$ and $\psi$ (more markedly in $\Delta$ ) could be detected during the induction period. Figure 5 shows that some of these changes in $\Delta$ were significantly outside the range of experimental errors.

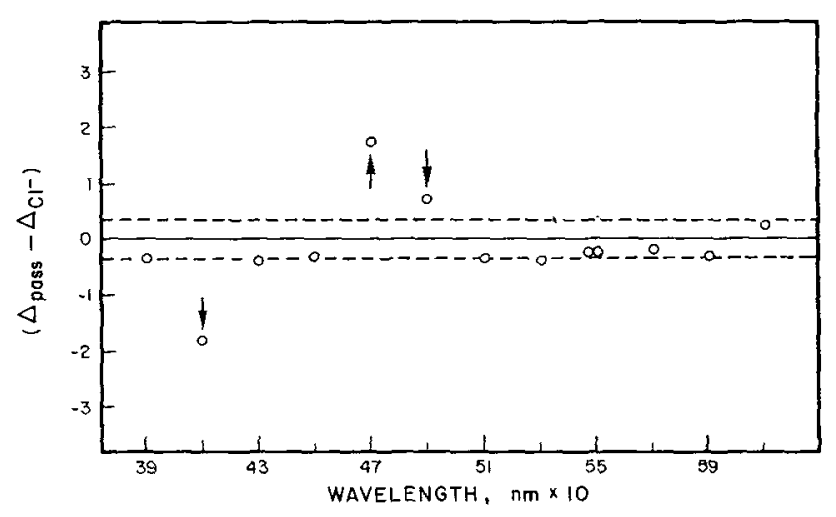

Frg. 5. - The difference between the $\Delta$-values obtained for a film grown on $\mathrm{Fe}$ at $1000 \mathrm{mV}$ SHE in buffered borate solution without chloride $\left(\Delta_{\text {pass }}\right)$ and with $0.005 \mathrm{~N}$ chloride $\left(\Delta_{\mathrm{C}_{1}-}\right)$ is shown as a function of wavelength. Arrows indicate the only wavelengths where the two $\Delta$ values differ by more than the error value. (From [28]).

Since changes in $\Delta$ and $\psi$ occur during the induction period at a few wavelengths, it is possible to follow these changes as a function of time by working at any one of these wavelengths. Figure 5 shows that, indeed, continuous variations in $\Delta$ and $\psi$ occur during the induction period until pitting is initiated (at the crosshatched area in Figure 6). Unambiguous determination of the optical constants for the passive film, and the changes in these constants with the addition of the chloride, were not made for reasons given elsewhere [6]. However, calculations were made which show that the changes in the film brought about by the chloride addition can alter the refractive index, $n$, and the absorption coefficient, $k$, at the affected wavelenghts, while producing no changes at the other wavelengths studied.

Figure 6 also shows other valuable details about the events occurring in connection with the induction period. First, it shows that if chloride is removed from the environment, the passive film will eventually recover its original $\Delta$ and $\psi$ values. Second, the time to breakdown and the time to recover depend strongly on the thickness of the passive film originally exposed 


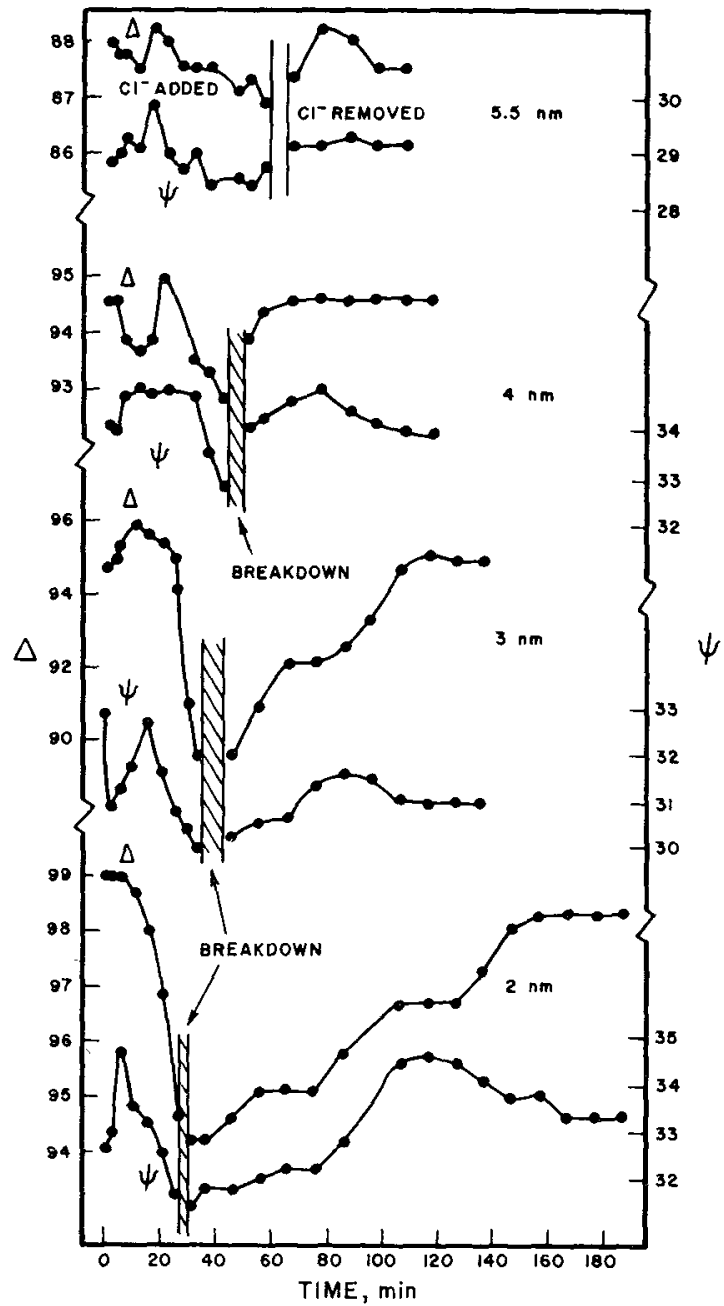

FIG. 6. - Modulations in $\Delta$ and $\Psi$ at $410 \mathrm{~nm}$ for prebreakdown and recovery processes are indicated for films of four thicknesses, $5.5,4.0,3.0$, and $2.0 \mathrm{~nm}$. (From [28]).

to the chloride. Finally, the extent of the optical change, $\Delta$ passive- $\Delta$ breakdown, is inversely proportional to the thickness of the passive film originally exposed to the chloride.

A recent study [30] showed how the results just described for iron can be strongly affected by alloying the iron with chromium and molybdenum. Figure 7 shows the effect of $\mathrm{Cl}^{-}$on the passive film grown on a $\mathrm{Fe}-20 \% \mathrm{Cr}$ alloy surface. The kinetics of optical change prior to breakdown are shown for measurements made at $450 \mathrm{~nm}$. Similar results were obtained at 390 and $410 \mathrm{~nm}$ also. The film was grown for 20 hours before the introduction of $\mathrm{Cl}^{-}$at a concentration of $0.08 \mathrm{~N} \mathrm{Cl}^{-}$. Experiments of a similar nature were also carried out on a Fe-24\% Cr alloy. The $\mathrm{Cl}^{-}$induced changes in $\Delta$ and $\psi$ were found to be less pronounced the higher the chromium content. As Figure 7 shows, the changes observed for the $\mathrm{Fe}-\mathrm{Cr}$ alloys are much less pronounced than for previous measurements made on pure Fe. More striking, however, is the fact that the films on the Fe-Cr alloys could not be made to recover their original optical values when $\mathrm{Cl}^{-}$was removed

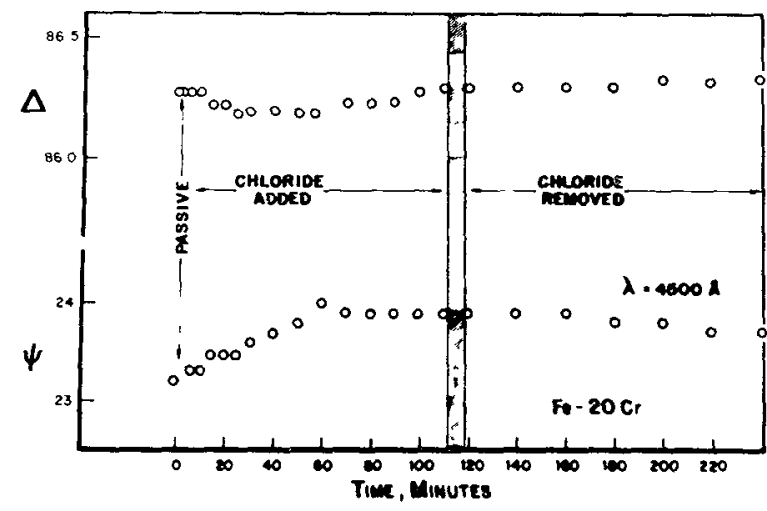

Fig. 7. - Spectro-ellipsometric measurements of changes in $\triangle$ and $\Psi$ for $\mathrm{Fe}-20 \mathrm{Cr}$ after introduction of chloride $(t=0)$, and removal of chloride from solution. $\Delta$ and $\Psi$ do not return to passive values once chloride ions are removed. $450 \mathrm{~nm}$ wavelength light was used. (From [30]).

from the solution as figure 6 shows is the situation for films on pure $\mathrm{Fe}$. Moreover, when $\mathrm{Cl}^{-}$was again added after an attempted recovery of the films on $\mathrm{Fe}-\mathrm{Cr}$ alloys, the breakdown that was interrupted by $\mathrm{Cl}^{-}$ removal occurred in times as short as 12 minutes.

The kinetic response of passive films on $\mathrm{Fe}-\mathrm{Cr}$ alloys to $\mathrm{Cl}^{-}$can then be summarized as : (1) difficult to break down; (2) little parameter response with time due to the $\mathrm{Cl}^{-}$addition; and (3) no recovery of the passive state upon removal of $\mathrm{Cl}^{-}$environments.

When $\mathrm{Mo}$ is added to an $\mathrm{Fe}-\mathrm{Cr}$ alloy, the results shown in figure 8 are obtained. It can be seen that the behaviour observed is not markedly different from that found for the $\mathrm{Fe}-\mathrm{Cr}$ alloy without Mo shown in figure 8.

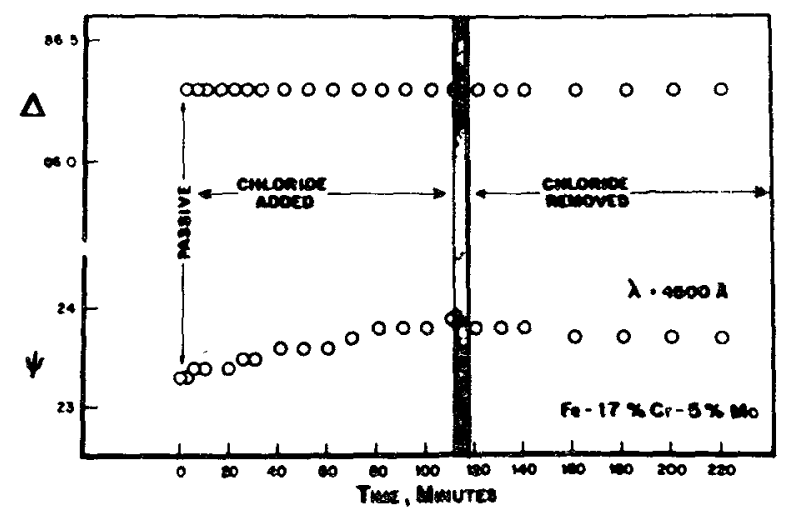

FIG. 8. - Spectro-ellipsometric measurements of changes in $\Delta$ and $\Psi$ for $\mathrm{Fe}-17 \mathrm{Cr}-5 \mathrm{Mo}$ after introduction of chloride $(t=0)$, and removal of chloride ions from solution. $450 \mathrm{~nm}$ wavelength light was used. (From [30]).

These results, therefore, indicate that $\mathrm{Mo}$, unlike $\mathrm{Cr}$, does not enhance the resistance of a passive film to $\mathrm{Cl}^{-}$ entry. It could also indicate that Mo is not present in the film at all as Auger results of Lumsden and Staehle [31] have indicated. Recent work by Ambrose and Kruger [32] has indicated that Mo may improve resistance to breakdown by enhancing the rate of 
repassivation. It may play this role by going into solution as a molybdate which would enhance the rate of repassivation.

c) Potential effects on breakdown. - All of the experiments described above were concerned with surfaces held at a potential above that necessary to initiate pitting, the critical pitting potential, $E_{\mathrm{c}}$. Many workers [33] believe that pits will not initiate at potentials below $E_{\mathrm{c}}$. Others [34] believe that if one waits long enough pitting will initiate below $E_{\mathrm{c}}$. This disagreement may arise because of the use of different techniques for measuring $E_{\mathrm{c}}$. Ellipsometry, however, does reveal that one can distinguish entirely different optical behaviour between passivated surfaces exposed to chloride well below and well above most commonly accepted values of $E_{\mathrm{c}}$.

It can be shown (Fig. 9) that passive film growth starting with a bare iron surface, proceeds in an identical fashion in solutions containing chloride to that observed for solutions without damaging ions when the potential at which the film is grown is below $E_{\mathrm{c}}$. When, however, the potential is above $E_{\mathrm{c}}$, chloride in the aqueous solution promotes rapid film growth. This type of growth is similar to that observed at time $t_{2}$ and is attributed to the deposition of a nonprotective corrosion product film as described earlier. Therefore, ellipsometry shows that potential has a profound effect on events occurring after pit initiation occurs.

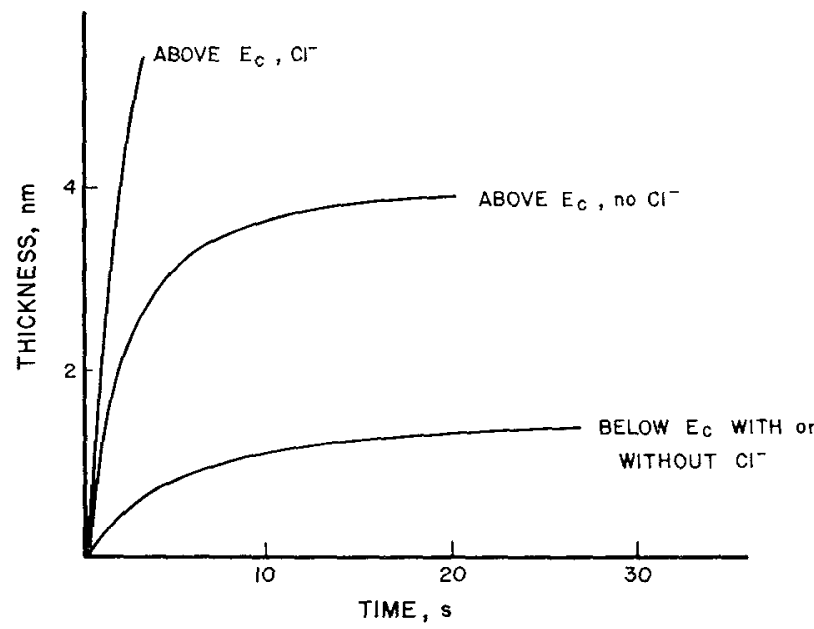

Frg. 9. - The effect of potential on film growth in the absence and presence of chloride ion $\left(10^{-2} \mathrm{M}\right)$ in boric acid-sodium tetraborate buffer solution $(\mathrm{pH}=8.4)$. Potentials were above $\mathrm{E}_{\mathrm{c}}($ at $0.64 \mathrm{~V} \mathrm{SHE})$ and below $E_{\mathrm{c}}($ at $-0.11 \mathrm{~V})$. Film thickness was measured by ellipsometry. (From [27]).

Potential can also affect the processes occurring prior to breakdown when chloride is introduced. Above $E_{\mathrm{c}}$, as described earlier, the introduction of chloride produces changes in the ellipsometric parameters, especially $\Delta$, at only a few wavelengths. Below $E_{\mathrm{c}}$, however, figure 10 shows that approximately equal changes in $\Delta$ occur at every wavelength when chloride ions are

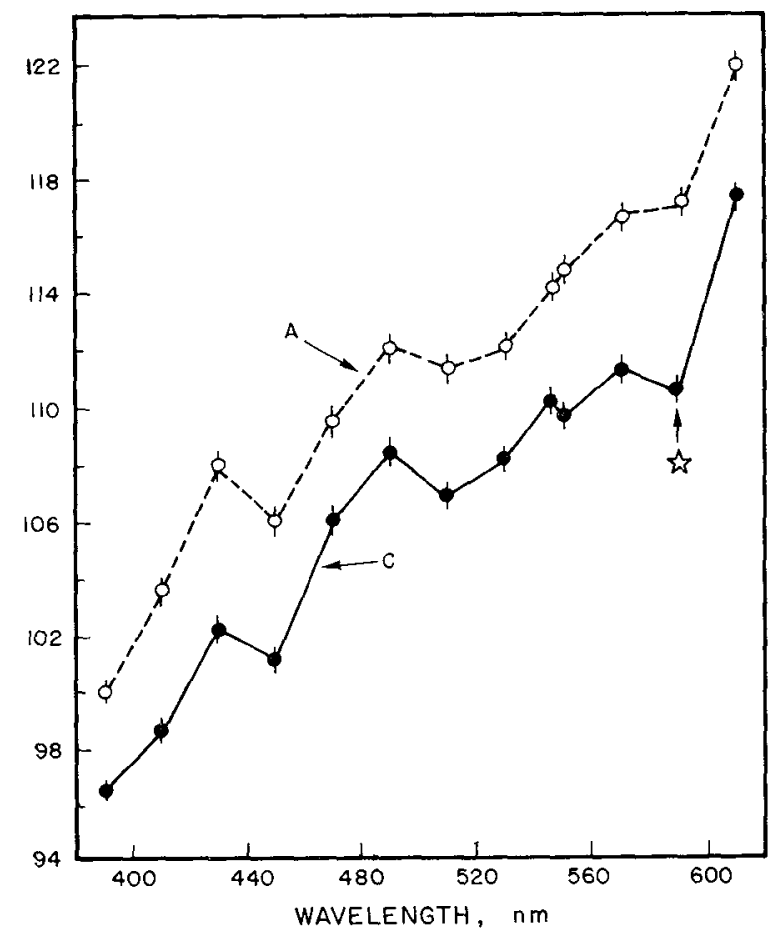

FIG. 10. - Curve $A$ represents the values of $\Delta$ obtained at $-100 \mathrm{mV}$ SHE for $\{221\}$ Fe in borate solution. Curve C shows the changes in the spectrum that occur when chloride is added to the solution. The star indicates that the spectra are not similar at $590 \mathrm{~nm}$. (From [28]).

introduced. This essentially uniform decrease in the overall $\Delta$ values, except perhaps at $590 \mathrm{~nm}$, accompaned by mainly insignificant changes in the $\psi$ spectrum indicates an increase in film thickness. An increase in film thickness can be caused by either the adsorption of chloride on top of the film or further growth of the passive film. It is also possible that both of the above mentioned processes take place concurrently. Calculations show that the magnitude of the changes in $\Delta$ and $\psi$ require a change in film thickness of at least $1.5 \mathrm{~nm}$. This is too large to be accounted for by only chloride adsorption. At any rate, for surfaces at potentials below $E_{\mathrm{c}}$, calculations show that the ellipsometric spectra indicate changes in film thickness (usually by a downward shift in $\Delta$ and insignificant changes in $\psi$ ) rather than changes in the film properties, as would be indicated by irregular movements in the $\Delta$ and $\psi$ values at discrete wavelengths.

These ellipsometric studies thus reveal that potential may affect much more than the kinetics of pit initiation. They reveal that subtle changes in the passive film itself are affected by the potential at which it is exposed to chloride, and these changes must be related to the tendency for the film to break down when the potential is above $E_{\mathrm{c}}$.

3.3 INITIATION OF CREVICE CORROSION. - Once it starts, crevice corrosion bears some similarities to pitting corrosion, in that both forms of localized cor- 
rosion propagate because of restricted mass transport of reactants or reaction products. In the case of pitting, mass transport is restricted because of corrosion products deposited on top of the pit and, in the case of the crevice, because of the existence of some material that restricts mass transport, e. g., gaskets, another piece of metal, a deposit of dirt, etc. Ambrose (see [35]) has described how one can apply ellipsometry to the study of processes occurring inside a crevice by creating a crevice with a glass plate on top of the metal surface to be studied (Fig. 11). Use of such transpa-

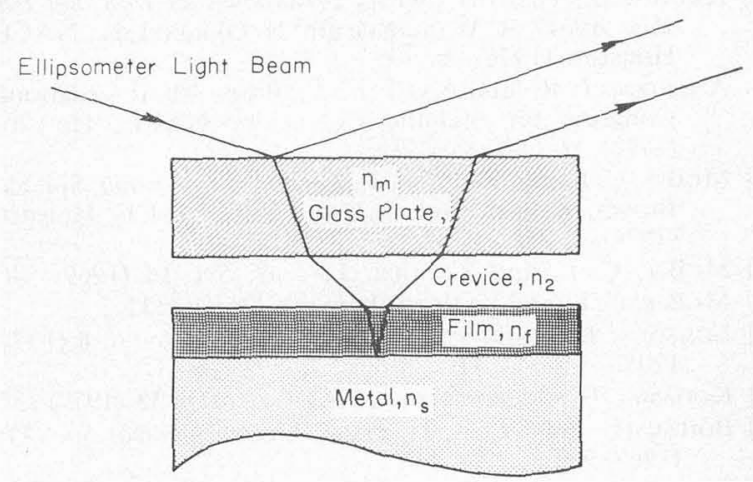

FIG. 11. - Model of the crevice system showing refraction of polarized light in various media. (From $\left[35_{c}\right.$ ).

rent windows for visual observation of a crevice is not new, but the results from such studies have been limited to detection of crevice corrosion in its advanced stages. The optical technique of ellipsometry, however, not only permits measurement of small changes in thickness and optical properties of surface films on metal substrates, but can perhaps be used to detect changes in composition of aqueous media as well. One can only hope to gain qualitative indications of the changes because the system is extremly complicated from an ellipsometric point of view. Besides the complications of the bottom surface on the glass plate which can be a surface for the adsorption of films and the changing index of refraction of the solution in the crevice, there exist the possibilities of passive film growth or dissolution, the deposition of corrosion products on the glass or metal and the effects of metal roughening once crevice corrosion has commenced. I will show, however, that this application of ellipsometry can provide additional information that helps in the interpretation of electrochemical results by being able to detect small changes occurring early in the chain of events leading to crevice corrosion and being able to determine at what time these changes occur.

Using the apparatus shown in figure 11, ellipsometric observations of the metal surface in a crevice produced results of the sort shown in figure 12 . With the surface held at the initial immersion corrosion potential $(+42 \mathrm{mV}), \Delta$ values decreased markedly during the first $20 \mathrm{~min}$. of exposure $\left(\delta \Delta=\sim-0.12^{\circ}\right)$

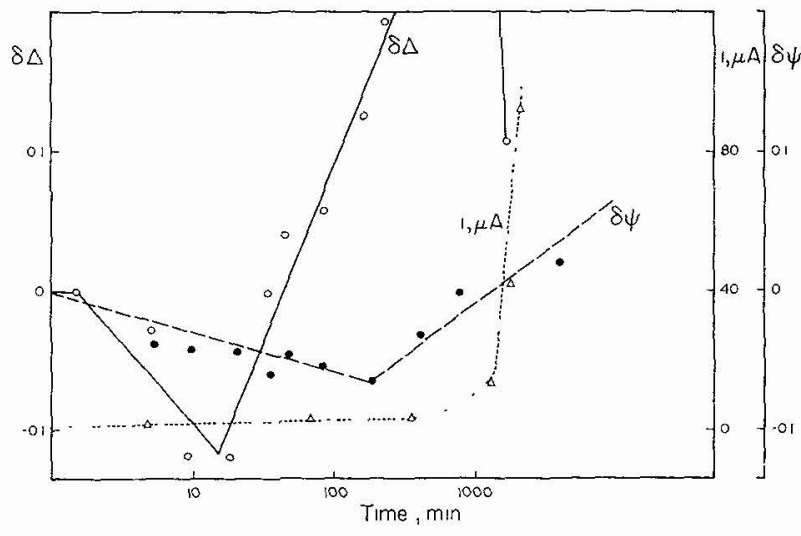

Fig. 12. - Effect of a crevice on ellipsometer parameters $\Delta$ and $\Psi$, and the corrosion current as a function of $\log _{10}$ time or 304 stainless steel in $1.0 \mathrm{~N} \mathrm{NaCl}$; specimen is potentiostated at $+42 \mathrm{mV}$ SHE. (From [35]).

before increasing to a maximum value $\left(\delta \Delta=+0.60^{\circ}\right)$, after about $1450 \mathrm{~min}$. The $\psi$ values fluctuated a great deal but, in general they decreased during the first 200 min. $\left(\delta \Delta=-0.65^{\circ}\right)$ then increased for the remainder of the exposure period. Current values slowly increased from $+0.66 \mu \mathrm{A}$ to a final value of $300 \mu \mathrm{A}$ at the end of the run. The major increase in the current, which indicates an increase in corrosion rate, occurred at about the same time that the $\Delta$ values started to decrease sharply. It is worth noting that, while large optical changes occur, virtually no electrochemical changes are observed until the current increase signals the onset of crevice attack. The optical changes are those that presumably lead to the initiation of this attack.

Kruger and Ambrose [36] interpreted the three stages of $\Delta$-changes in figure 11 as being due to the following :

First stage : An increase in the refractive index of the solution in the crevice.

Second stage : A thinning of the protective film.

Third stage: A roughening of the metal surface and deposition of corrosion products after the breakdown signalled by a precipitous increase in current.

Although these mechanistic inferences are consistent with the observed ellipsometric variation, they are by no means the only possible interpretation. This is so because the ellipsometric measurements reflect average overall changes occurring under the glass plate. In other words, one process - i. e., solution concentration - could easily mask out small changes in the film/metal substrate. Much further work is necessary to make ellipsometric observations of crevices more definitive and quantitative. However, the results just described are important qualitatively because they indicate the times at which changes occur in the crevice in the processes leading to crevice attack. Moreover, a reasonable picture, consistent with the optical measurements of events initiated during these changes can be developed using measurements in special environments with a crevice. 


\section{References}

[1] Winterbotrom, A. B., Optical Studies of Metal Surfaces, Kgl. Norske Videnskab Selskabs Skriften 1955, Vol. 1, F. Bruns Bockhandel, Trondheim (1955).

[2] Kruger, J. and Calvert, J. P., J. Electrochem. Soc. 114 (1967) 43.

[3] Harvey, W. W. and Kruger, J., Electrochem. Acta 16 (1971) 2017.

[4] ORd, J. L., Surf. Sci. 56 (1976) 413.

[5] Cahan, B. D., Surf. Sci. 56 (1976) 354.

[6] Agrus, B. and SrecjkA, J., J. Electrochem. Soc. 122 (1975) 723.

[7] HAYFiELD, P. C. S. and WhITE, G. W. T., Ellipsometry in the Measurement of Surfaces and Thin Films, Passaglia, Stromberg and Kruger, Eds. (U. S. Government Printing Office, Washington, D. C.) 1964, p. 157.

[8] HaYField, P. C. S., Surf. Sci. 56 (1976) 488.

[9] KRUGer, J. and HAyfreld, P. C. S., Handbook on Corrosion Testing and Evaluation, W. H. Ailor, Ed. (J. Wiley \& Sons, New York) 1971, p. 783.

[10] FenstermaKer, C. A. and MCCRACKIN, F. L., Surf. Sci. 16 (1969) 85.

[11] OHLIDAL, I. and Lukes, F., Opt. Acta 19 (1972) 817.

[12] Sмiтн, T., Surf. Sci. 56 (1976) 252.

[13] Kruger, J., Corrosion 22 (1966) 88.

[14] Bockris, J. O'M., Genshaw, M. and Brusic, V., Optical Studies of Adsorbed Layers at Interfaces, Symposium of the Faraday Soc., No. 4, 177 (1970).

[15] Green, J. A. S., MengelberG, H. D. and Yolken, H. T. J. Electrochem. Soc. 117 (1970) 433.

[16] Archer, R. J. and Gobeli, G. W., J. Phys. Chem. Solids 26 343 (1965).

[17] ARCher, R. J., ref. [7], p. 255.

[18] Strachan, C., Proc. Cambridge, Philos. Soc. 29 (1933) 116.
[19] MeYer, F. and Bootsma, G. A., Surf. Sci. 16 (1969) 221.

[20] Ambrose, J. R. and Kruger, J., Proc. 5th Intl. Cong. on Metallic Corrosion, Tokyo, NACE, Houston (1974), p. 406.

[21] Ambrose, J, R. and Kruger, J., I. Electrochem. Soc. 121 (1974) 599.

[22] Ambrose, J. R, and Kruger, J., Corrosion 28 (1972) 30.

[23] Leidheiser, H. and Kellerman, E., Corrosion 26 (1970) 99.

[24] SCuLLY, J. C. and HoAR, T. P., 2nd Int. Congress on Metallic Corrosion, NACE, Houston (1970), p. 184.

[2S] KRUGER, J., Adv. in Electrochem. and Electrochem. Eng., Vol. 9, R. H. Muller, Ed. (J. Wiley \& Sons, New York) 1973, p. 227.

[26] Kruger, J., Passivity and its Breakdown on Iron and Iron Base Alloys, R. W. Staehle and H. Okada, Eds., NACE, Houston (1976), p. 91.

[27] Ambrose, J. R. and Kruger, J., Proc. 4th International Congress on Metallic Corrosion, NACE, Houston (1972), p. 698 .

[28] MCBee, C. L. and Kruger, J., Localized Corrosion, Staehle, Brown, Kruger, and Agrawal, Eds., NACE, Houston (1974), p. 252.

[29] McBee, C. L. and KRuger, J., Surf. Sci. 16 (1969) 340.

[30] MCBeE, C. L. and Kruger, J., in ref. [26], p. 131.

[31] Lumsden, J. B. and Staerle, R. W., Scr. Metall. 6 (1972) 1205.

[32] Kodama, T. and Ambrose, J. R., Corrosion 33 (1977) 155.

[33] BoHNI, H. and UhLIG, H. H., J. Electrochemical Soc. 116 (1969) 906.

[34] PRYOR, M. J., in ref. [28], p. 2.

[35] KRUGER, J. and AmBrose, J. R., NBS Report NBSIR 73-224, September (1974).

[36] Kruger, J. and Ambrose, J. R., Surf. Sci. 56 (1976) 394.

\section{DISCUSSION}

W. PAASCH. - What is your interpretation of the changes of $\Delta$ and $\psi$ during the induction period in the case of pitting attack? We got very similar results investigating $\mathrm{Ni}$ and $\mathrm{Ti}$ in halide solutions using modulation spectroscopy and according to our opinion, these changes in the optical properties are due to surface field strength effects.

J. KRUGER. - We have speculated that they are due to the formation of color centers, but I emphasize that these are only speculations.

M. Costa. - Il semble que dans vos expériences l'accroissement de la rugosité se traduise par une diminution de $\Delta$. Dans des expériences que nous avons effectuées sur l'or nous avons à l'inverse pu expliquer une augmentation de $\Delta$ par la rugosité.

J. KRUGER. - We have never studied gold, so that I cannot say whether the change in $\Delta$ with roughness would differ in direction from that we observed on iron. Many parameters are involved in measuring roughness effects (angle of incidence, wavelength, the nature of the films on the rough surface, etc...). However, a paper by Ohlidal, Navratil and Lukes (Folia Facultatis Scientiarium Naturalium universitatis Purkinianae Brunensis XV (1974)) shows theoretically that for most metals (gold included) $\Delta$ decreases in absolute value with roughness.

I am not sure whether this agrees with your results or mine.
B. Aguis. - Pour montrer que la rugosité se forme, entre autre, aux joints de grains, vous avez obtenu des variations différentes de $A$ pour un échantillon monocristallin et polycristallin. Avez-vous observé des variations identiques pour $\psi$ ?

J. KRUGER. - The parameter $\psi$ does vary in the same direction as $\Delta$, but to a much lower extent. This agrees with some theories of roughness.

F. LUKES. - One comment on the determination of surface roughness as was shown in our previos publications (see I. Oklidal, F. Lukes and K. Navratil) the surface roughness, more precisely to say, the increasing value $\tan \beta$ characterising the slopes of surface irregularities generally decreases $\psi$ value for materials with optical constants $n_{1} \approx k_{1}$ and $n_{1}<k_{1}$, it means for most metals. In our notation it increases $\Delta$ value (decreases the absolute value). That means that it is possible at least to estimate from the qualitative character of $\Delta$ and $\psi$ whether experimentally found change of $\Delta$ and $\psi$ may be caused. By roughnening of the surface or not. If we know reasonably precisely some optical parameters of the system under consideration, we can even determine the value $\tan \beta_{0}$ from $\Delta$ and $\psi$ studied in the way described in Dr. Kruger's paper.

J. KRUGER. - This is a very interesting comment. Perhaps your approach could be used to estimate corrosion rates if one assumes a rather uniform roughening on the average. 